\title{
Characterization of mixed mode crack opening in concrete
}

\author{
Jacobsen, Jonas Sejersbøl; Poulsen, Peter Noe; Olesen, John Forbes
}

Published in:

Materials and Structures

Link to article, DOI:

$10.1617 / \mathrm{s} 11527-011-9754-5$

Publication date:

2012

Link back to DTU Orbit

Citation (APA):

Jacobsen, J. S., Poulsen, P. N., \& Olesen, J. F. (2012). Characterization of mixed mode crack opening in concrete. Materials and Structures, 45(1-2), 107-122. https://doi.org/10.1617/s11527-011-9754-5

\section{General rights}

Copyright and moral rights for the publications made accessible in the public portal are retained by the authors and/or other copyright owners and it is a condition of accessing publications that users recognise and abide by the legal requirements associated with these rights.

- Users may download and print one copy of any publication from the public portal for the purpose of private study or research.

- You may not further distribute the material or use it for any profit-making activity or commercial gain

- You may freely distribute the URL identifying the publication in the public portal

If you believe that this document breaches copyright please contact us providing details, and we will remove access to the work immediately and investigate your claim. 


\title{
Characterization of Mixed Mode Crack Opening in Concrete
}

\author{
J. S. Jacobsen • P. N. Poulsen • J. F. Olesen
}

Received: date / Accepted: date

\begin{abstract}
In real concrete structures cracks often open in mixed mode after their initiation. To capture the direct material behavior of a mixed mode crack opening a stiff biaxial testing machine, capable of imposing both normal and shear loads on a given crack area, has been applied. The opening and sliding components of the mixed mode displacement are measured using a custom made orthogonal gauge, and the measurements are used directly as the closed loop control signals. A double notch, concrete specimen is used for the crack investigation. The tests are divided into two steps, a pure Mode I opening step, where a macro crack is initiated in the specimen followed by the mixed mode opening step. The high stiffness of the set-up together with the closed control loop ensures a stable crack initiation followed by a controllable mixed mode opening. The deep notches result in a plane crack, only influenced by material aspects such as the aggregate size and concrete strength. Despite the occurrence of a few, local, secondary cracks during the mixed mode crack opening, the results can be treated as the mixed mode material point behavior of a crack in concrete. Results are reported for a range of mixed mode angles and for varying initial Mode I openings of the crack.
\end{abstract}

Keywords Biaxial loading - Concrete · Mixed Mode Fracture · Constitutive behavior

\section{Introduction}

When the stresses in reinforced concrete structures exceed the concrete tensile capacity and thereby activate

J. S. Jacobsen · P. N. Poulsen · J. F. Olesen

Department of Civil Engineering, Technical University of Denmark, Kongens Lyngby, Denmark

E-mail: jonse@byg.dtu.dk the reinforcement, cracks will initiate and propagate in the concrete and between concrete and reinforcement. In general the cracks will open in mixed mode after the initiation, i.e. a combined opening and sliding between the crack faces in an already established crack. For a realistic model of the general structural behavior or the detailed deterioration conditions concerning the structure, the modeling of the mixed mode crack opening is crucial. Thus, it is important to have consistent models for the crack behavior both in the concrete and in the interface between concrete and reinforcement.

The initial loading results in micro cracks in the concrete. For increasing load the micro cracks will start to coalesce and finally lead to the formation of macro cracks. As proposed by Hillerborg et al. [7] with the fictitious crack model, cracks in concrete can be simplified as a single crack in a concrete block. This idealized crack is then ascribed some constitutive behavior covering e.g. the geometric effects of the crack and the influence from the surrounding micro cracking. Thus the cracking in concrete can be modeled at different scales. At the micro level, modeling aggregates, mortar paste and interlayer, geometric effects such as the roughness are included in the model. Thus, a constitutive Coulomblike relation including cohesion, but without dilation, can be used. However, modeling at the micro scale is very demanding in terms of computational resources. So, modeling real size structures, it is advantageous to use a macro scale model where the micro cracking effects are included in the larger cracks through the constitutive crack model.

The crack initiation and the Mode I opening behavior are well described in the fictitious model by Hillerborg et al. [7]. The crack initiation is assumed to take place in pure Mode I, perpendicular to the largest principal stress. After the crack has been initiated there 
is nothing that prevents the crack faces from undergoing sliding as well, i.e. opening in mixed mode. A softening elastoplastic model for the opening-sliding mode has been proposed by Carol et al. [1]. The model is Coulomb-like and uses a fracture energy based damage parameter as control variable for the yield surface contraction, however, the model lacks reversible frictional behavior. The reversible frictional behavior is included in the model by Nielsen et al. [9] which is based on a new Coulomb-like yield surface. The model is elastoplastic with damage and has a cohesional and a frictional part. The frictional part includes deformation state dependency, where the friction decreases with crack opening and is restored with crack closure.

Experimental results from a direct determination of the mixed mode behavior form an essential basis for constitutive model development and verification. Previously significant biaxial set-ups have been presented by Nooru-Muhamed [10] and Hassanzadeh [5]. NooruMuhamed developed a setup in which three frames were used to induce the mixed mode loading condition. The stiffness of the set-up is not reported and the crack patterns reported by Nooru-Muhamed consist of cracks which initiate from each notch and propagate in a curved pattern without joining into a single crack. Such a crack pattern may only form an indirect basis for the determination of the mixed mode behavior. Hassanzadeh developed a set-up suited for mounting in a standard testing machine, and the mixed mode loading condition was established with a separate second axis. Hassanzadeh introduced a crack under Mode I opening followed by a mixed mode opening, which lead to a more direct determination of the mixed mode behavior. However, the crack patterns reported include some secondary cracking undermining the direct determination of the crack behavior. Again the stiffness of the set-up is not documented and there are humps on the descending branch, which normally are associated with insufficient stiffness, see e.g. Hillerborg [6].

Another biaxial set-up was presented by Østergaard et al. [14] and consists of a stiff support structure and a separate second axis. The mixed mode loading condition is established by mounting both the support structure and the second axis in a standard testing machine. Østergaard et al. tried two different shaped concrete specimens. First they used a dog bone shaped specimen, but the geometry lead to multiple cracks and an initial cracking, which was very difficult to control. The second specimen was a double notch concrete block which had a side length of $150 \mathrm{~mm}$ and a depth of $100 \mathrm{~mm}$. The relatively high specimen introduced a large amount of elastic energy in the set-up, and the larger elastic energy made the fracture initiation unstable and ex- tremely difficult to control. Therefore, according to the stiffness considerations, the specimen dimensions were reduced by Petersen [11] to the dimensions $150 \times 80 \times 75$ $\mathrm{mm}^{3}$ with a notch depth of $37.5 \mathrm{~mm}$, see Fig. 1. The significant lower height reduced the amount of elastic energy. Both Østergaard et al. and Petersen used the piston displacements as the control signal. According to Petersen this resulted in a large deviation between the prescribed ratio between opening and sliding, i.e. the mixed mode angle, and the actual angle achieved. The large deviation made it difficult to control the test and made an inverse analysis of the test results necessary.

Another type of specimen partly concrete, partly steel has also been used to investigate the mixed mode behavior, Walter \& Olesen [16]. The specimen is inserted in a standard uniaxial testing machine, and the level of mixed mode is prescribed by the inclination of the separation between the two materials with respect to the loading direction. However, for larger mixed mode angles the simple uniaxial set-up results in long specimens with low stiffness and thereby an unstable testing. Pre-notched beams in 3 point bending have also been used to characterize cracks in concrete under mixed mode loading, see e.g. Carpinteri \& Brighenti [2]. The level of mixed mode is dictated by the position of the notch with respect to the three supports/loadings. The beam test gives the beam response to the applied loading but it is very difficult to interpret the mixed mode material behavior of the crack, and the test can only provide an indirect crack interpretation. Reinhardt et al. [12] and Reinhardt \& Xu [13] suggest a method for Mode II testing in pure concrete. A shear stress state is establish by loading one side of a double notch specimen in compression, parallel to the notch direction, while the other side is unsupported. The method investigates the Mode II fracture toughness, however, since the specimen is not pre-cracked the mixed mode behavior of a crack is not revealed.

In order to capture the direct material behavior of mixed mode fracture, a biaxial testing machine, which is capable of imposing both normal and shear loads on a given crack area, is needed. This paper presents such a set-up and a series of mixed mode results for an already established crack in a double notch, concrete specimen. The present set-up is an enhancement of the set-up by Østergaard et al. [14], where the control is changed such that the vertical and the horizontal axis can be controlled independently in a closed control loop. Referring to Gettu et al. [3], a more stable and robust fracture control is obtained by using the actual opening and sliding over the ligament in the control. The measurements of the opening and sliding are ob- 


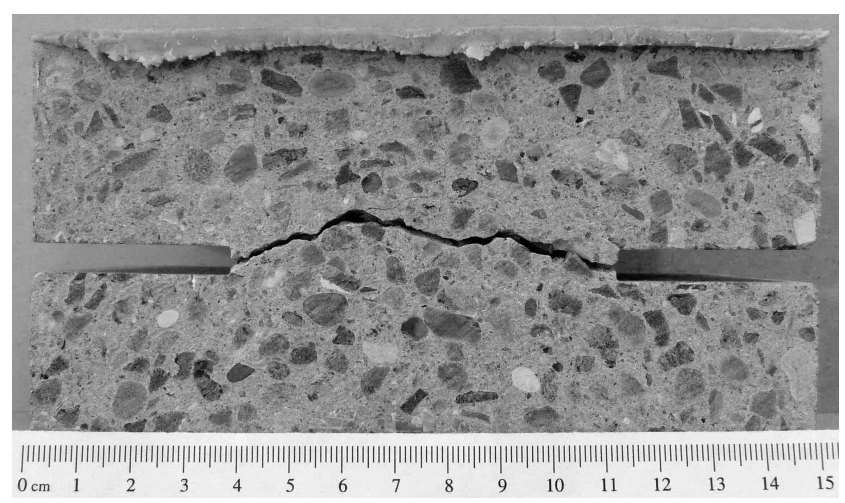

Fig. 1 Test specimen in the configuration with short notches. Curved crack path between notches.

tained by using a custom made gauge rail mounted on the specimen.

For small initial openings followed by a mixed mode loading, the specimen dimensions by Petersen [11] clearly result in structural like response with either a curved crack path, as in Fig. 1, or a secondary failure in a new inclined crack, running away from the ligament area. By sawing the notches deeper to the present depth of $55 \mathrm{~mm}$, each test results in a single, primary crack between the two notches and a reduced amount of secondary cracks. Further, the deeper notches reduce the structural effects and result in a plane crack, allowing for a more direct material interpretation. Altogether the present set-up gives reliable material tests for a direct characterization of mixed mode fracture in concrete.

The following section presents the test set-up in the new configuration, the specimen and the applied concrete, the orthogonal gauge rails used for mounting the clip gauges in a close vicinity of the crack and the test procedure.

Characteristic results from mixed mode tests, displaying relevant mixed mode ratios between opening and sliding for a single crack, are presented and analyzed.

\section{Test Set-up}

The idea with the set-up is to measure the material point behavior for a single crack in a pure concrete specimen. It is believed that the crack initiation takes places in pure Mode I, perpendicular to the largest principal stress. But after the initiation the crack can be exposed to both opening and sliding, i.e. mixed mode. In the fictitious crack model by Hillerborg et al. [7] the initiated crack, or the macro crack, is assumed to be formed when the largest principal stress over the crack area reaches the tensile capacity. Hillerborg et al. states that actually the crack is still an accumulation of micro cracks
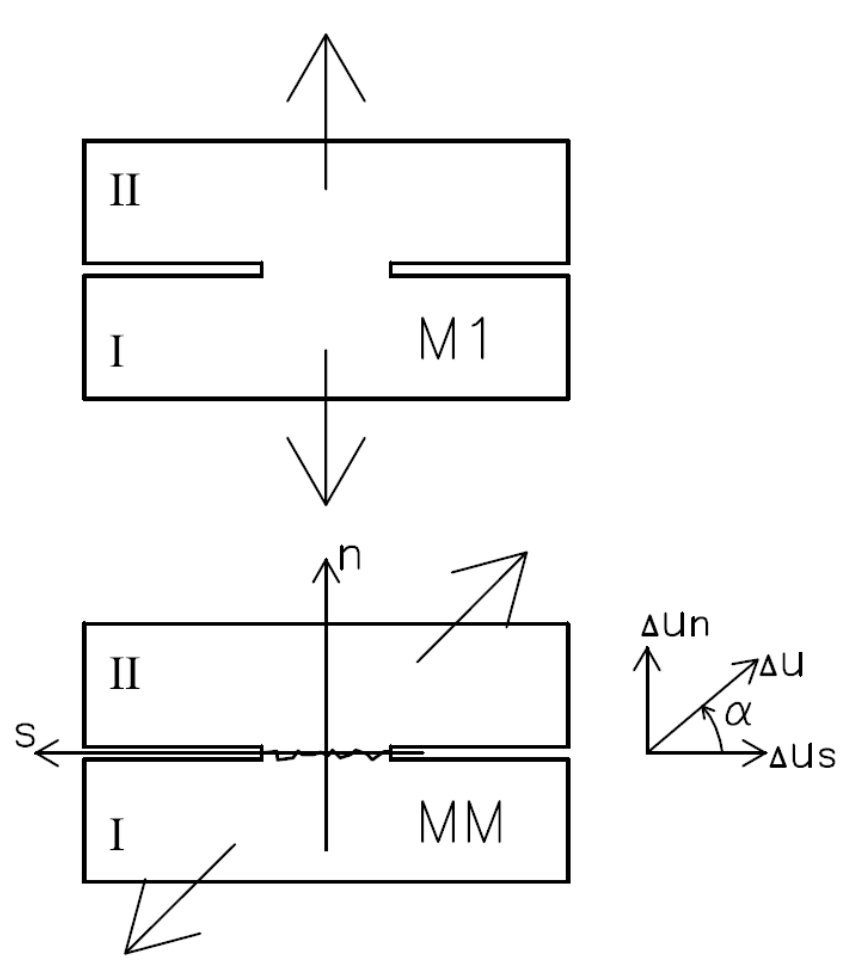

Fig. 2 The two test steps, the Mode I opening step, MI, and the mixed mode step, MM. At the mixed mode step the local $(n, s)$ coordinate system and direction of positive relative displacements between the two specimen parts, I and II, are indicated and the mixed mode angle $\alpha$ is defined.

and that the coalescence of micro cracks into a macro crack happens once the cohesion is exhausted. Though the macro crack is observed by Østergaard et al. [14] to be formed before the cohesion is exhausted. Østergaard et al. reports that the initial crack band between the notches, i.e. the macro crack, is established when the tension load has decreased to around $50 \%-70 \%$ of the maximum tensile capacity. So, to make a proper mixed mode crack test of and already established crack, the test must be divided in to two steps, see Fig. 2. The first step is the crack initiation in a pure Mode I opening until the macro crack is fully initiated, followed by the second step, the mixed mode opening.

The biaxial setup by Østergaard et al. [14] has been enhanced with a new improved closed control loop and is modified to the new specimen dimensions, but the principle build up is the same. The set-up consists of a four column $5 \mathrm{MN}$ universal testing machine and then a built in second axis. The four column $5 \mathrm{MN}$ testing machine ensures a stiff frame for the set-up as illustrated on Fig. 3, and supports the motions in the two perpendicular directions. The support structure ensures that the two axes are geometrically independent, and the set-up has separate control valves for the hydraulic supply for the two axes. 


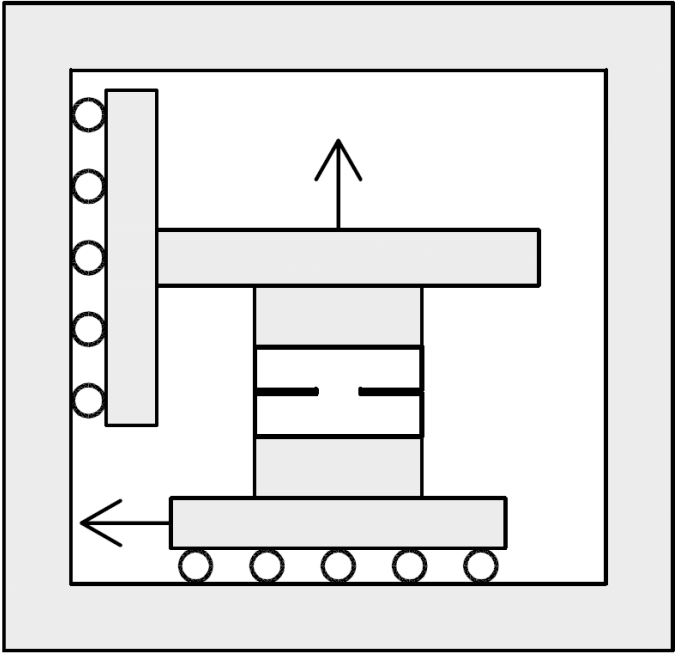

Fig. 3 The principle idea of the set-up with the stiff frame supporting the motions of the two axes. Displacement directions are indicated.

\subsection{Testing Machine}

Fig. 4 shows the overall structure of the machine. The machine consists of two independent actuators and is controlled by a multi-axial Instron 8800 control unit. A four column Instron $5 \mathrm{MN}$ universal testing machine is the basis of the set-up, giving a very stiff and full functional vertical axis of loading. The horizontal axis is designed especially for the set-up and built into a very stiff support structure, such that the shear load is carried from the actuator through the specimen and back to the actuator through compression in the support structure. Thereby this custom made bi-axial hydraulic testing machine has a considerable rotational stiffness. The stiffness was measured by Østergaard et al. [14] and is given as the translational stiffness $K_{m, t}$ $=500 \mathrm{kN} / \mathrm{mm}$ and the rotational stiffness as $K_{m, r}=$ $8000 \mathrm{kNm} / \mathrm{rad}$. Compared to the actual maximum load used in the test, which is between $10-20 \mathrm{kN}$, the stiffness is considerable. Further, keeping in mind that the set-up has a closed control loop, the measuring length and thereby the impact from the elasticity of the set-up is negligible.

The motions of the test specimen are conducted through two slides, a horizontal and a vertical. The slides, which can be seen in Fig. 5, are constructed from low friction and high precision THK linear motion systems with oversized balls in the closed ball bearings. All bolted connections in the set-up are pre-stressed such that no slip between the steel plates can occur during the experiment. The specimen is glued into the set-up using sandblasted steel blocks. During the gluing pro-

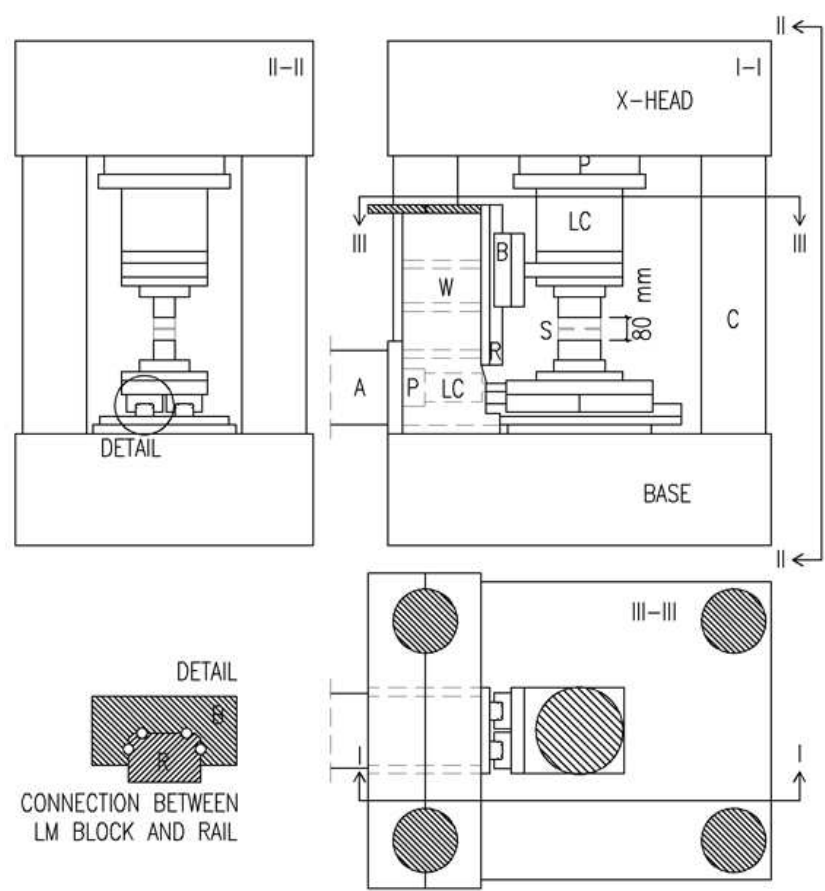

Fig. 4 Sketch of biaxial set-up. $\mathrm{A}=$ actuator, $\mathrm{P}=$ piston, $\mathrm{LC}$ = load cell, $\mathrm{S}=$ specimen, $\mathrm{C}=$ column, $\mathrm{B}=$ linear motion block (LM block), $\mathrm{R}=\mathrm{Rail}, \mathrm{W}=$ web. Some background details are left out for clarity.

cess the set-up is in load control, avoiding that stresses arise in the specimen during the hardening.

The control in the present set-up is improved such that the vertical and the horizontal axes can be controlled independently by separate closed loop controls. Measurements of the opening and sliding are obtained by using specially designed gauge rails mounted on the specimen, see Fig. 6 . In the vertical direction the load is measured using the load cell from the four column testing machine, while the horizontal load is measured by a load cell placed in immediate continuation of the horizontal slide, see Fig. 4. The set-up has been designed for $500 \mathrm{kN}$ in the vertical direction and $250 \mathrm{kN}$ in the horizontal direction. In the present set-up however, the load cells limit the capacity to $100 \mathrm{kN}$ and $50 \mathrm{kN}$ in the vertical and horizontal direction, respectively, giving a better load resolution at lower loads. The testing machine is capable of imposing both normal and shear loads on a given crack area and together with the closed control loop, the set-up has proven to give an accurate determination of the mixed mode behavior in concrete.

\subsection{Test Specimen}

In Fig. 5 the test specimen is shown in place in the testing machine. The double notch test specimen has a 


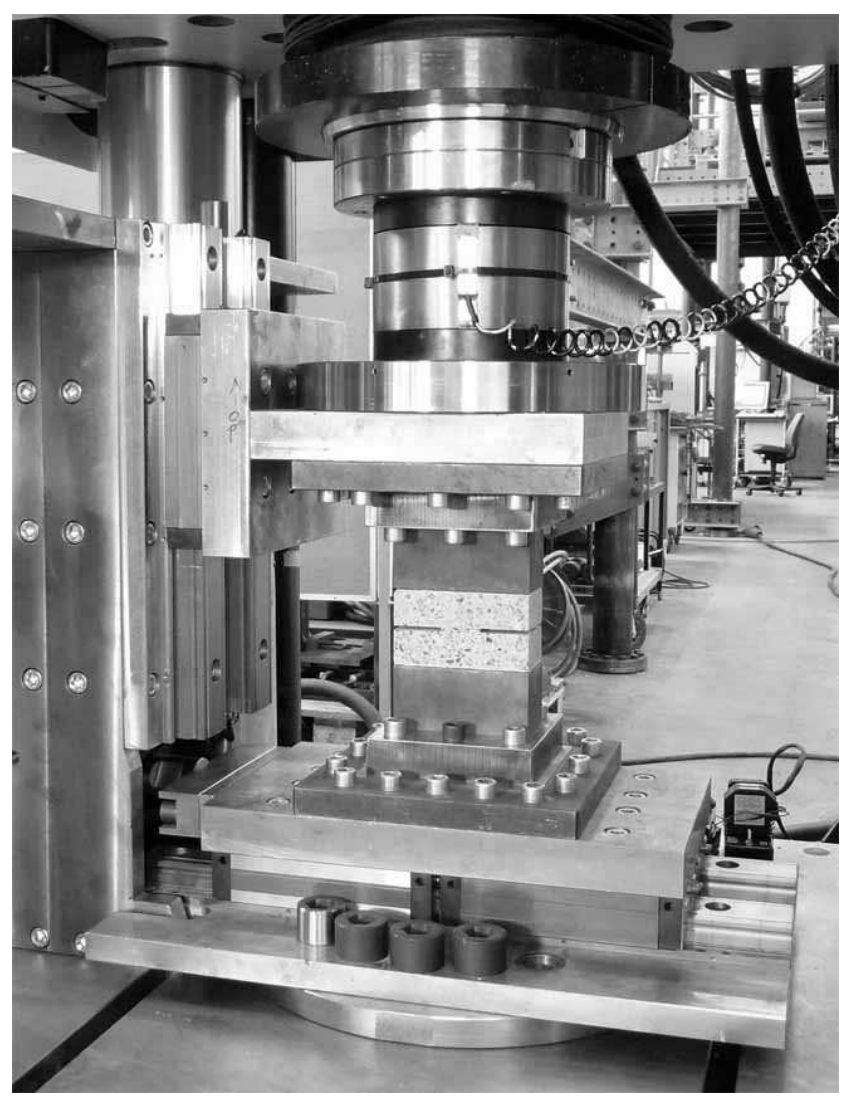

Fig. 5 Test set-up showing a glued in test specimen, vertical load cell, support structure and the slides in both vertical and horizontal direction.

Table 1 Mix design.

\begin{tabular}{ll}
\hline Mix & $\mathrm{kg} / \mathrm{m}^{3}$ \\
\hline Cement (Portland Basis) & 290 \\
Water & 184 \\
Sand, 00-04 mm & 933.8 \\
Aggregates. 04-08 mm & 928.5 \\
\hline
\end{tabular}

width of $150 \mathrm{~mm}$, a height of $80 \mathrm{~mm}$ and a depth of 75 $\mathrm{mm}$. The notches are cut from the side and have a depth of $55 \mathrm{~mm}$. Thereby the ligament area is $40 \times 75 \mathrm{~mm}^{2}$. The specimens are cut from a beam with a cross section of $150 \times 150 \mathrm{~mm}^{2}$ and a length of $600 \mathrm{~mm}$. The deep notches ensure that a single, fairly plane crack develops between the two notches, ensuring that results can be considered as material point information.

The concrete has a maximum aggregate size of $8 \mathrm{~mm}$ and a predicted 28 days strength of $30 \mathrm{MPa}$, the mix design is shown in Table 1 . The beams were de-molded after $24 \mathrm{~h}$ and then cured in $100 \%$ humidity at $20{ }^{\circ} \mathrm{C}$ for 40 days. The testing was carried out in between 45 to 65 days from the mixing day, and the compression strength was measured in a standard cylinder test to $41 \mathrm{MPa}, 42$ days after the mixing.

\subsection{Gauge Rails}

A local $(n, s)$-coordinate system is introduced according to Fig. 2. Fracture in the ligament divides the specimen in two parts, I and II, respectively. Relative displacements between the two parts, $\Delta u_{n}$ and $\Delta u_{s}$ in the $n$ and the negative $s$ direction, respectively, are defined as

$\Delta u_{n}=u_{n}^{I I}-u_{n}^{I}$
$\Delta u_{s}=u_{s}^{I}-u_{s}^{I I}$

In the test the relative displacement $\Delta u$ is assumed to be constant along the ligament. The relative displacements are measured by four Clip Gauges (CGs) mounted on the specimen using two custom made orthogonal gauge rails placed across the two notches. In pair the CGs measure the deformation in vertical and horizontal direction, respectively. The CGs allow for independent control of the vertical and horizontal axis in a closed control loop using the mean signal in respective directions as the response signal.

Fig. 6 shows the principle structure of the orthogonal gauge rails, and Fig. 7 shows gauge rails and CGs in use. Two small, high precision THK miniature Type LM Guides, [15], are used in each orthogonal gauge rail. Low friction oversized ball bearings together with the CGs allow for the determination of displacements smaller than $1 \mu \mathrm{m}$. The rails are assembled orthogonally through the blocks top on top, and a specially designed house around the blocks together with modified end blocks enables the attachment of CGs. At the front of the specimen the gauge rail has three supports, two at one side of the notch supporting the horizontal rail and one at the opposite side supporting the vertical rail. The two horizontal supports and the vertical support can move independently, allowing for the measuring of the relative displacement in both directions between the two parts of the specimen. The gauge rail is kept in place by an aluminum arm clamping around the specimen. At the back, the aluminum arm's point support is placed close to the centre of the triangle defined by the three front supports.

As illustrated by Madsen [8], who used a pair of CGs mounted directly on the specimen, the test set-up is fully capable of performing full uniaxial opening histories and cyclic loading histories on the actual concrete specimens. Further, with the gauge rails the following illustrates that the set-up enables stable closed loop controlled mixed mode testing. 


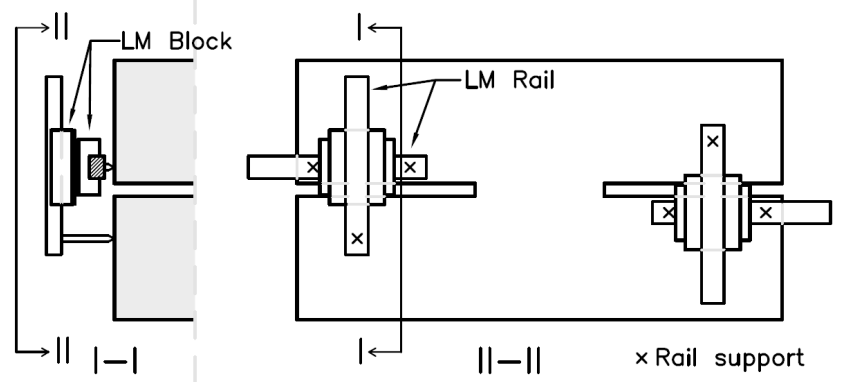

Fig. 6 Principle sketch of gauges rails with Linear Motion (LM) rails, LM blocks and indication of rail supports.

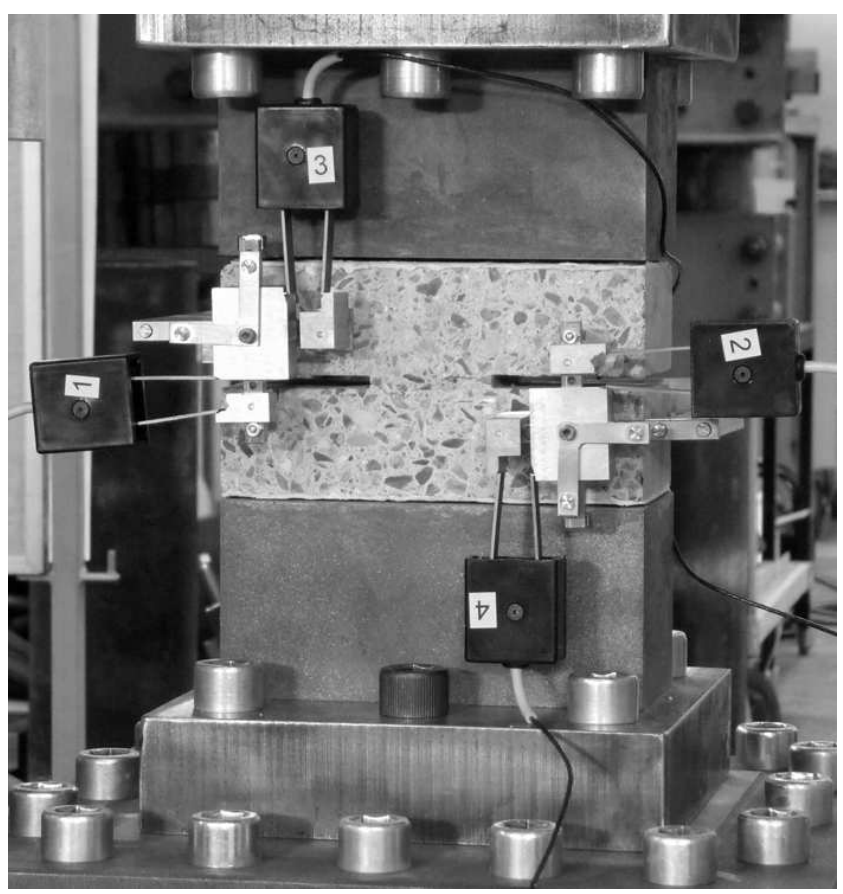

Fig. 7 Close view of test specimen, gauges rails and clip gauges.

\subsection{Test Procedure}

Initially a crack is introduced between the notches by a pure Mode I opening, $\Delta u_{s}=0$, and the crack is opened to a specified crack opening measured by the CGs. After the initiation of the crack the specimen can be exposed to both Mode I and II opening introducing a mixed mode opening of the crack. The mixed mode opening angle, $\alpha$ in Fig. 2, is defined as the angle between the horizontal plane and the relative displacement, i.e.

$\tan (\alpha)=\frac{\Delta u_{n}}{\Delta u_{s}}$

The initial, vertical displacement velocity is $0.1 \mu \mathrm{m} / \mathrm{s}$, while the mixed mode opening pace is gradually increased to a final opening pace of $2.0 \mu \mathrm{m} / \mathrm{s}$. Displacement velocity is set such that the peak load corresponding to $f_{t}$ is captured in around $60 \mathrm{~s}$ and the test in total

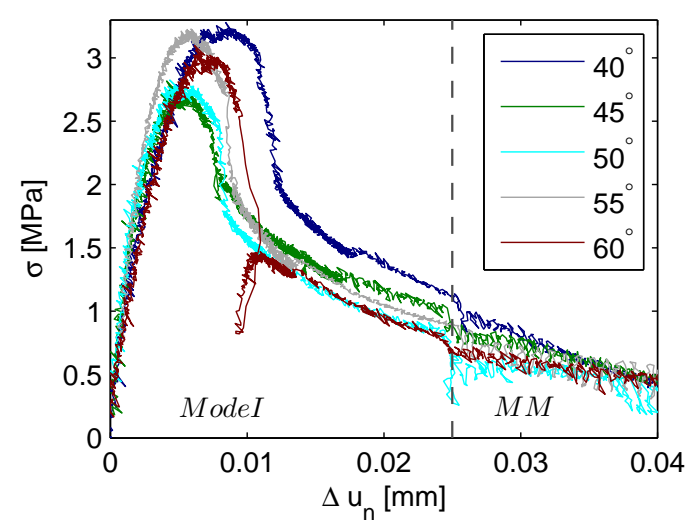

Fig. 8 Initial load opening displacement curves for four different mixed mode angles. The dashed line indicates the start of mixed mode displacement (MM).

is finished in around $600 \mathrm{~s}$. Slow opening pace ensures a more stable crack initiation, while the total time is limited in an attempt to limit the influence of viscoelastic effects.

\subsection{Aramis}

Along with the CG signals the displacements are recorded by the high-resolution digital image correlation system Aramis by GOM mbH [4]. The Aramis system is a $3 \mathrm{D}$ photometric equipment and uses digital stereo photographing and subsequent triangulation to determine $3 \mathrm{D}$ displacements on the observed surface of the specimen. The system enables determination of the displacement field in a close vicinity of the crack. The four megapixels picture, with side lengths $\mathrm{h} \times \mathrm{h}$, is divided into small regions called facets, which here consist of 15 $\times 15$ pixels. During the analysis the movement and deformation of the facets is registered and assembled. This analysis gives a displacement field of the surface, which e.g. can be post-processed into a strain field. Fig. 9a - e show typical results from the Aramis system. The displacement resolution is approximately $\mathrm{h} \times 10^{-5}$ and in the present case $\mathrm{h}=120 \mathrm{~mm}$. The strain calculation is based on the engineering strain determined from the relative displacement between the facets.

\section{Results}

\subsection{Load Opening Displacement}

At first the test specimen is loaded in pure tension with respect to the ligament between the two notches. This Mode I loading initiates a crack between the notches 
and results in a characteristic opening-displacement response shown in Fig. 8. The normal stress $\sigma$, defined as the measured normal load divided by the ligament area, is plotted as function of the opening displacement $\Delta u_{n}$ for different test specimens. During the loading in the elastic domain, the different tests almost coincide, while their maximum points are scattered over an interval of $0.5 \mathrm{MPa}$. After the maximum point the same scatter interval continues during the fracture initiation. The scatter is most likely caused by the natural variation of concrete properties. In four of the five cases the test set-up is able to capture the softening branch and in the last case, for an additional opening, the softening branch is recaptured. These opening curves prove the sufficient stiffness of the test set-up. Starting the mixed mode at an opening of $\Delta u_{n}=0.025 \mathrm{~mm}$ clearly results in a drop in the normal stress but also some more noise caused by the combined loading in mixed mode. Further, it is shown that starting the mixed mode displacement at an opening of $\Delta u_{n}=0.025 \mathrm{~mm}$ corresponds to a load level of $30-40 \%$ of $f_{t}$.

The nature of the crack surface introduces some scatter. At a given opening, the surface has a certain shear capacity. At a larger opening or caused by some damage in the crack surface, e.g. a rotating grain, the shear capacity may be exceeded. Exceeding the shear capacity introduces a sudden but limited drop in the load level, and thereby some scatter in the results. The scatter is most distinct in the mixed mode phase, however, since the crack is not completely plane, the frictional scatter is also present in the Mode I. The noise in the load-displacement curves in Fig. 8 is very limited during the Mode I opening, while the mixed mode opening increases the amount of scatter.

Besides the frictionally related scatter some electronic noise may also occur in the results. The two axes are hydraulically independent and connected only through the specimen. Noise recognized is primarily caused by tuning difficulties with the closed loop control. Stiffness of the specimen changes remarkably during the test, which makes it difficult to find a single tuning level for the entire test, and some noise is expected. The noise is reduced after the peak by an increase in displacement rate and thereby an indirect change in the tuning of the closed control loop signal. Fig. 8 shows the original test data while the following mixed mode results have been filtered to emphasize the overall mixed mode behavior. The filtering is based on a running mean method, where the maximum shear load in an interval is found. The interval length corresponds to 20 data records of raw data, approximately equal to 2 seconds of testing time. These 20 data records are reduced to the one representing the maximum shear load.

\subsection{Aramis Example}

The photometric system Aramis is used to locate the crack pattern at the specimen surface, see Sect. 2.5 for details about Aramis. Fig. 9 shows the fracture propagation during a mixed mode test. The discrete cracking is illustrated by the use of the largest principal strain registered on the surface. The notion of strain is normally not valid in combination with localized cracking, and the strain measure is only for visualization purposes. After the crack initiation the specimen is displaced in a mixed mode angle of $\alpha=50^{\circ}$, giving a bit more opening than shear. Fig. 9f shows the normal stress $\sigma$ and the shear stress $\tau$ plotted as functions of the opening displacement $\Delta u_{n}$. Stress stages for the matching pictures are indicated. The average stresses $\sigma$ and $\tau$ are defined as the measured normal and shear load divided by the ligament area, respectively.

The first picture, Fig. 9a, shows the fracture development at peak load and clearly indicates that the macro crack between the notches is not fully established. Same observation is made by Petersen [11] and by Østergaard et al. [14], who state that a clear crack establishment is not obtained until the load has decreased by 20 - $50 \%$ of the peak load. As shown in Fig. 8, the load, at the beginning of mixed mode displacement, is reduced to $30-40 \%$ of the peak load. At this displacement level clear crack localization is obtained, see Fig. 9b. The test is displacement controlled, so after some mixed mode loading the dilational effects will shift the normal load from tension to compression and thereby build up some confinement over the ligament area. Fig. 9c is snapped directly at this transition and despite a clear, primary crack some secondary cracks tend to grow in crack planes inclined with respect to the ligament area. At maximum compression multiple secondary cracks have formed, see Fig. 9d, but for the fracture propagation a clear primary crack between the two notches is still seen. The last picture, Fig. 9e, shows the final fracture development for loads returning to zero, and a clear fracture area is localized representing some secondary cracks and an distinct primary opening crack.

As seen in Fig. 9 the crack between the notches is not completely straight and the crack pattern also includes some secondary cracking. The crack path is influenced by the aggregates and the current stress state. The sliding introduces some secondary cracks in one or more crack planes located outside the ligament area. If the sliding is dominant compared to the opening, one or more of the secondary cracks may end up being the primary one and the specimen may fail due to a secondary fracture. In this case the test has failed. But if 


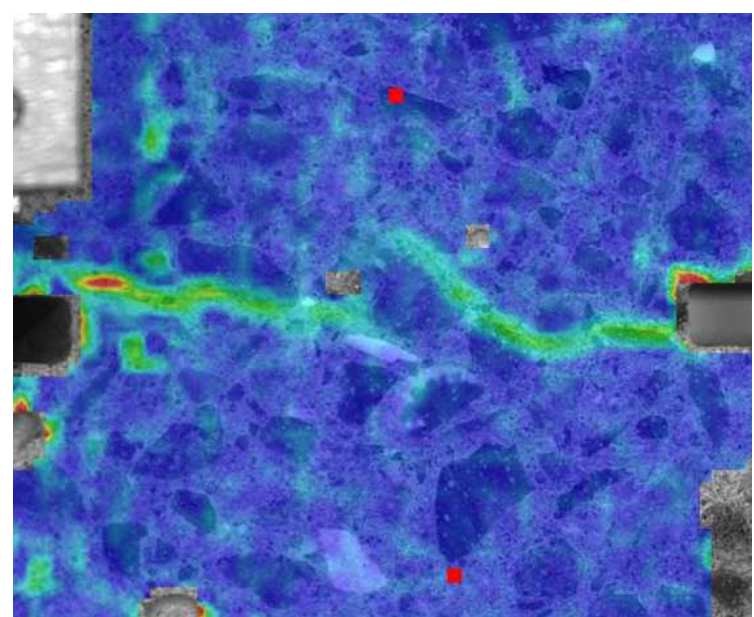

(a) Crack initiation for mixed mode angle of $\alpha=50^{\circ}$. Maximum tension, crack not fully initiated.
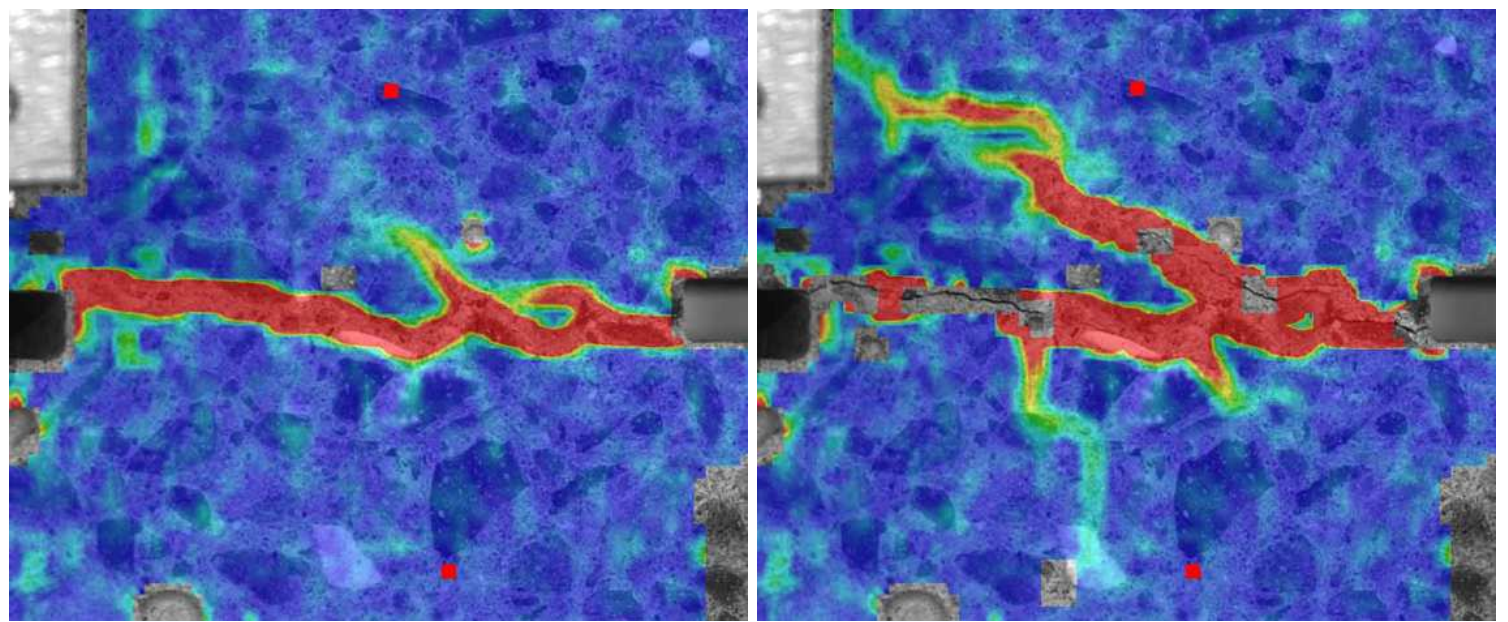

(c) Normal stress changing from tension to compression, (d) initiation of secondary cracks. ondary cracks and visible opening crack.
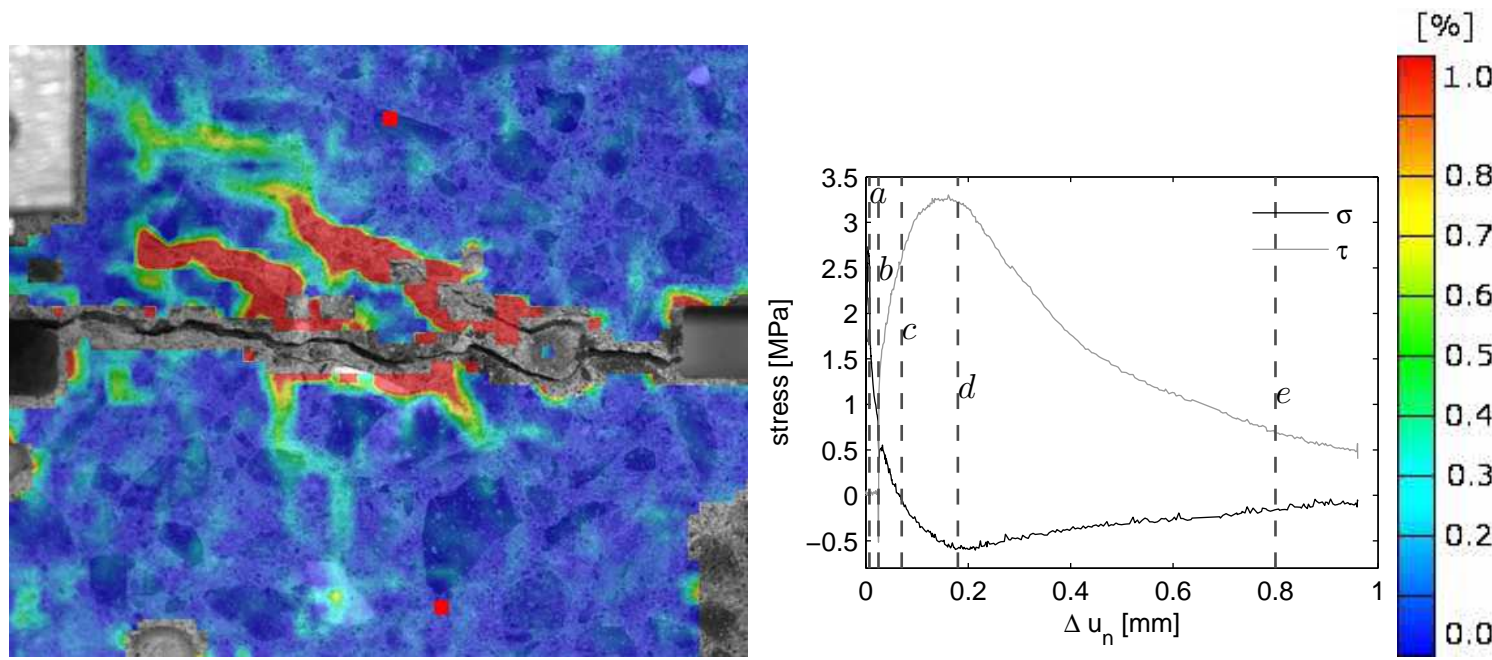

(e) Final crack pattern with clear primary crack and some (f) Stress opening relation indicating test progress for the secondary fracture primary localized at the right notch.

different Aramis pictures, Fig. 9a - e. Strain scale for Aramis pictures made transparent, which make it possible to see the aggregate location.

Fig. 9 Crack initiation and mixed mode opening for the initial opening $\Delta u_{n}=0.025 \mathrm{~mm}$ and the mixed mode angle $\alpha=50^{\circ}$. 


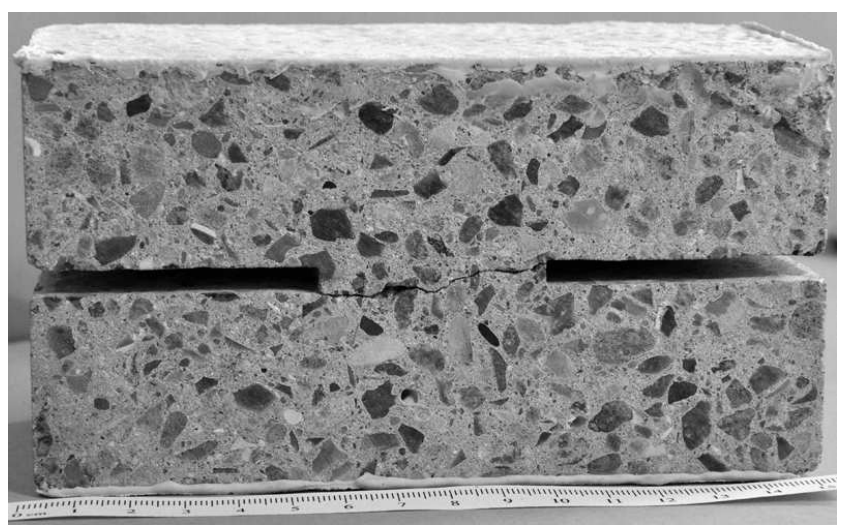

Fig. 10 Final crack path for the $40^{\circ}$ mixed mode test.

the end state consists of a primary crack between the two notches, possibly with some local secondary cracking, the results are considered as the material information for a single, plane crack.

\subsection{Crack Morphology}

The test specimens are casted from a concrete with varying aggregate size up to $8 \mathrm{~mm}$, and the concrete as a material is far from being homogenous. Therefore a completely straight crack path will not be possible. However, the crack path in the present tests is almost straight, with a variation smaller than or equal to the notch height of $4 \mathrm{~mm}$, see e.g. Fig. 9e for $50^{\circ}$ mixed mode and Fig. 10 for $40^{\circ}$ mixed mode. This fracture localization between the notches is a characteristic of the new test specimen, and structural effects obtained with the old test specimen by Petersen [11], see Fig. 1, are avoided by the new deeper notches. Having a closer view of the crack surface, see Fig. 11 from the $40^{\circ}$ mixed mode test, it is clear that the fracture is localized in between the aggregates. Thereby the crack surface is influenced by the aggregate size but without the earlier reported structural effects. This plane fracture localization ensures that results may be considered as material point information.

\subsection{Mixed Mode Behavior}

The test combinations of initial openings and mixed mode angles are listed in Table 2. The combinations cover results ranging from an almost pure Mode I opening, $\left(\Delta u_{n}, \alpha\right)=\left(0.100 \mathrm{~mm}, 60^{\circ}\right)$, to an ending failure in one of the secondary cracks, $\left(\Delta u_{n}, \alpha\right)=\left(0.015,60^{\circ}\right)$. The secondary failure results in a new inclined primary crack, running away from the ligament area. For a larger initial opening the specimen can be displaced in a smaller

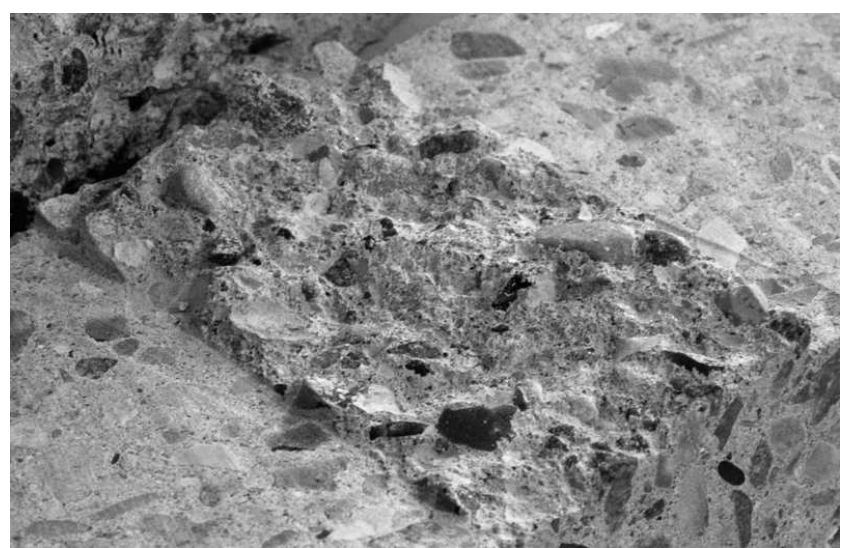

Fig. 11 Close view of the crack surface for the $40^{\circ}$ mixed mode test.

Table 2 Mixed mode test program, initial opening $\Delta u_{n}$ and mixed mode angle $\alpha$.

\begin{tabular}{lccccc}
\hline \multicolumn{7}{c}{$\Delta u_{n}[\mathrm{~mm}]$} \\
$\alpha$ & 0.015 & 0.020 & 0.025 & 0.040 & 0.100 \\
\hline $40^{\circ}$ & \multicolumn{7}{c}{+} \\
$45^{\circ}$ & & & + & + & + \\
$50^{\circ}$ & & + & + & + & - \\
$55^{\circ}$ & & + & + & - & \\
$60^{\circ}$ & + & + & - & & \\
+ & plane crack & & \\
+ & plane crack with local secondary cracking \\
+ & dominant secondary crack
\end{tabular}

mixed mode angle without introducing secondary cracks, while a smaller initial opening needs a larger mixed mode angle to avoid the secondary failure. The different tests indicate a band for combinations of interest, i.e. combinations where the mixed mode angle for the given initial opening is small enough to introduce some shear stresses and still high enough to avoid a secondary failure. The combinations $\left(0.015,60^{\circ}\right),\left(0.020,55^{\circ}\right)$ and $\left(0.025,45^{\circ}\right)$ almost result in a secondary failure with $\left(0.015,60^{\circ}\right)$ actual changing from a ligament crack to a secondary fracture during the test. In the other end the dilation caused by the sliding is balanced by the simultaneous crack opening, so the combinations $\left(0.025,60^{\circ}\right)$, $\left(0.040,55^{\circ}\right)$ and $\left(0.100,50^{\circ}\right)$ almost do not encounter any build up of compression stresses.

Fig. 12 and Fig. 13 show the mixed mode behavior for different combinations of initial opening and mixed mode angle, in Fig. 12 for constant initial opening of $\Delta u_{n}=0.025 \mathrm{~mm}$ and in Fig. 13 for constant mixed mode angle of $\alpha=50^{\circ}$. Together with the results listed in the Appendix A the figures represent the results for the combinations in Table 2.

In Fig. 12 the mixed mode behavior is presented for five specimens opened at five different mixed mode angles from $40^{\circ}$ to $60^{\circ}$ dictated by the closed control 
loop. In Fig. 12c the initial opening of $\left(\Delta u_{n}, \Delta u_{s}\right)=$ $(0.025,0) \mathrm{mm}$ in each test is recognized and after the opening the five different mixed mode angles can be read from the figure. Deformations in Fig. 12c are measured by the CG and are the actual responses to the demand, and even before the filtering they were almost without any noise. Fig. 12d is the load opening displacement similar to Fig. 8 but with interchanged axes and a considerable larger range of opening. The natural variation of the concrete is reflected in the variation in the tension strength in Fig. 8. So it is expected to see a scatter in both the compression stresses and the shear stresses. But by Fig. 12d for the normal stress, there is a clear correlation between the level of compression and the size of the mixed mode angle. Lowered mixed mode angle is equal to a higher level of sliding and thereby intensified dilational effects, which in the displacement controlled test result in more compression. The $40^{\circ}$ has the most compression followed by $45^{\circ}, 50^{\circ}$ and $55^{\circ}$ while the $60^{\circ}$ test has a compression level at almost zero. Responses for $45^{\circ}$ and $50^{\circ}$ are roughly identical, which probably is an effect of the natural variation of concrete properties. The spike for $40^{\circ}$ at maximum compression is caused by a change of fracture from a beginning shear crack away from the ligament to a more significant opening crack. Similar to Fig. 12d for normal stress, the shear stress level, shown together with the shear displacement in Fig. 12a, increases for lowered mixed mode angle where the sliding starts to dominate. The displacement controlled test introduces some confinement over the ligament and the ligament can thereby transfer a considerable amount of shear stresses, in these tests up to twice as high as the tensile strength. Fig. 12b combines the results from the three other plots and shows the shear stress, $\tau$, as function of the normal stress, $\sigma$. Despite the few tests there is a clear tendency in the mixed mode behavior, with almost straight lines in both loading and unloading before and after the peak in the stress-plot, respectively.

In Fig. 13 the mixed mode behavior is presented for four specimens with varying initial opening from $\Delta u_{n}=0.020 \mathrm{~mm}$ to $\Delta u_{n}=0.100 \mathrm{~mm}$ dictated by the closed control loop. The different initial openings together with the constant mixed mode opening of $50^{\circ}$, can be recognized from Fig. 13c. From Fig. 13a and 13d it is clear that the highest level of shear and compression is obtained for the smallest initial opening, and that the stress level drops for increasing initial opening, with almost no compression for $\Delta u_{n}=0.100 \mathrm{~mm}$. The normal stress level in Fig. 13d almost coincides for the two tests $\Delta u_{n}=0.020 \mathrm{~mm}$ and $\Delta u_{n}=0.025 \mathrm{~mm}$. Even though the difference between the two initial openings is not large it does represent a significant change of co- hesion. Therefore the almost coinciding curves are probably a consequence of the natural variation of concrete properties. In the $\sigma, \tau$-plot in Fig. 13b again there is a clear tendency in the mixed mode behavior, despite the few tests. The stress level increases for decreasing initial opening, and again there are almost straight lines in both loading and unloading before and after the peak in the stress-plot, respectively.

For the tests with constant initial opening, the $40^{\circ}$ test with the relative large amount of sliding almost results in a shear fracture. The $60^{\circ}$ test with a relatively large amount of opening is almost without any mixed mode effects. Similar to the tests with constant mixed mode angle the large initial opening of $\Delta u_{n}=0.100 \mathrm{~mm}$ is almost without any mixed mode effects, while it was impossible to conduct the same test for an initial opening of $\Delta u_{n}=0.015 \mathrm{~mm}$. The five tested mixed mode angles for the chosen initial opening, and the four different initial openings for the same mixed mode angle, cover the relevant test area from nearly encountering a shear fracture to an almost pure Mode I opening. In the stress plots in Fig. 12b and Fig. 13b the stress paths in mixed mode have almost straight lines in both loading and unloading, a Coulomb-like behavior. Overall there is a clear tendency that the shear level and the compression level raises for both decreasing initial opening and for decreasing mixed mode angle.

\section{Conclusion}

The mixed mode opening behavior of a crack is measured and the results are used to characterize the mixed mode material point behavior of a crack in concrete. The tests are conducted in two steps, a pure Mode I opening step, where a macro crack is initiated in a double notch specimen followed by the mixed mode opening step, i.e. a combined opening and sliding of the crack. A biaxial testing machine consisting of a $5 \mathrm{MN}$ universal testing machine and a built-in second axis has been applied to the mixed mode measurements. The set-up has a new enhanced closed control loop with the relative opening and sliding of the crack as the control signals. The opening and the sliding of the crack are measured by clip gauges using a custom made orthogonal gauge rail mounted on the specimen. The concrete specimens are designed with deep notches and are tested both for varying initial opening and for varying mixed mode angle.

Earlier reported biaxial set-ups have a lack of stiffness and the results often need to be analyzed through an inverse analysis to achieve the actual mixed mode material behavior. In Mode I, the present set-up is sufficiently stiff and, together with the closed control loop, 


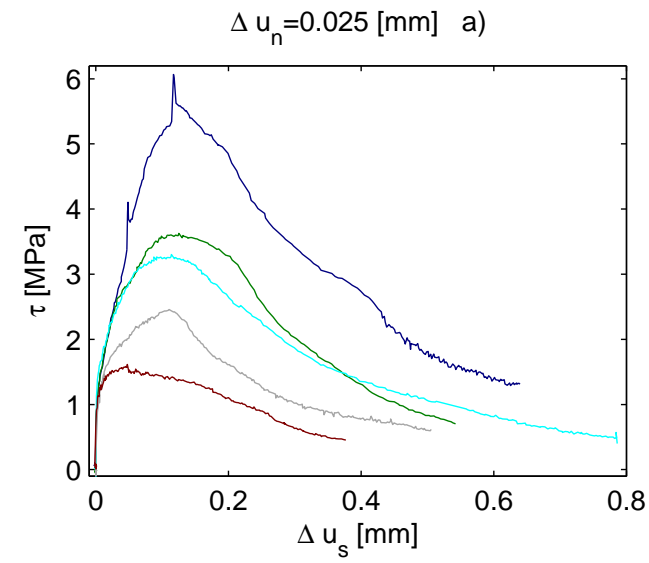

b)

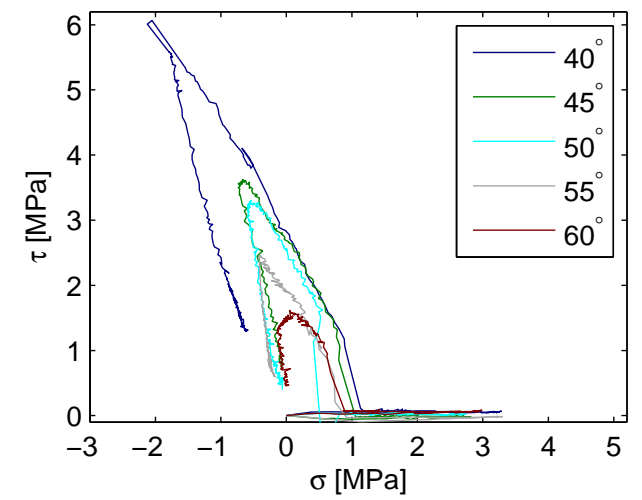

c)

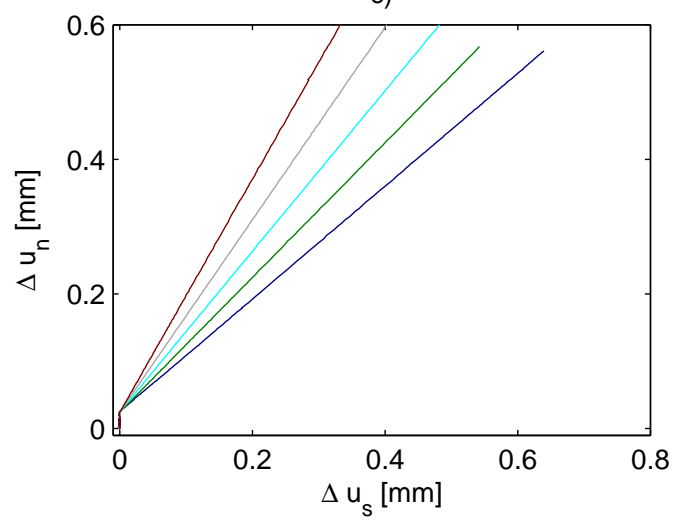

d)

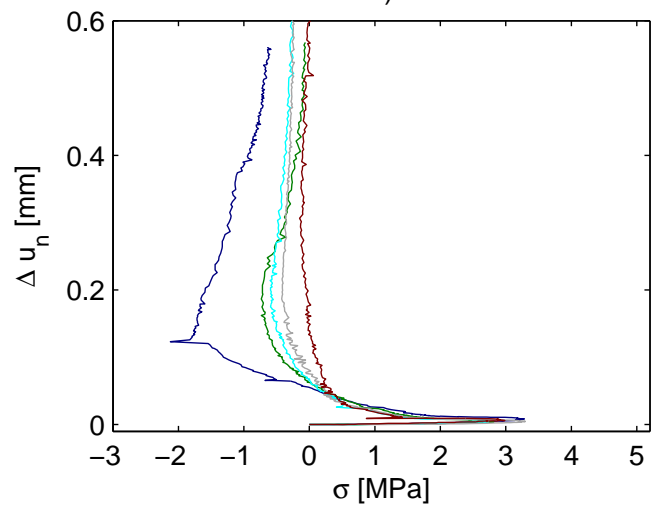

Fig. 12 Mixed mode test results for five different mixed mode angles with the same initial opening of $\Delta u_{n}=0.025 \mathrm{~mm}$.

it is capable of determining the crack initiation. The orthogonal gauge rail results in a direct interpretation of the mixed mode crack opening process, ensuring that the achieved response over the ligament is equal to the prescribed mixed mode angle. As a result of the specimen design and the set-up design, the crack surface is even and governed by material aspects like aggregate size and concrete strength rather than structural effects. Subsequent investigation of the total crack surface supports this interpretation. Despite the occurrence of a few local secondary cracks during the fracture development, the crack determination is representative of a single crack under mixed mode displacement; and the results are considered to be the mixed mode material point behavior of a crack in concrete.

A relative sliding between the two crack surfaces introduces dilational effects, which in the displacement controlled test results in some confinement over the crack. The confinement ensures that a considerable amount of shear stresses can be transferred over the crack, here up to twice as high as the tensile strength. A high level of shear and compression is obtained for a small initial opening and for a small mixed mode angle. The stress paths in mixed mode act in a Coulomb-like be- havior with almost straight lines in both loading and unloading. Further, there is a clear tendency that the shear level and the compression level raises for both decreasing initial opening and for decreasing mixed mode angle.

The crack determination from the material tests is considered representative of a single crack in mixed mode loading, and the results are well suited as a direct determined basis for the model development of a mixed mode material model. Based on the straight stress paths in mixed mode, it seems reasonable to represent the results by a Coulomb-like material model. Further, the results can be used to validate and calibrate already existing macro and micro mechanical material models for cracks in concrete.

\section{A Complete Mixed Mode Results}

The following figures together with Fig. 12 and Fig. 13 show the measured mixed mode behavior.

Fig. 14 shows tests for the $40^{\circ}$ mixed mode angle at three different initial openings. In the stress plot in Fig. 14b there are almost straight lines in both loading and unloading. The tendency is clear, the compression level and the shear level increases for decreasing initial opening. 

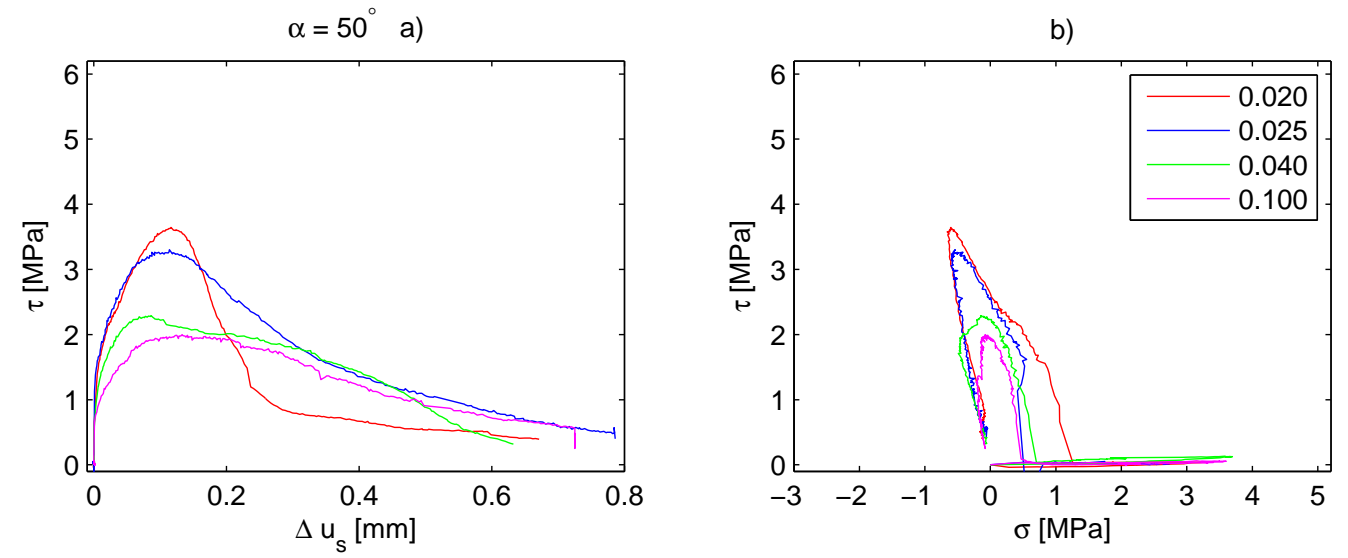

c)
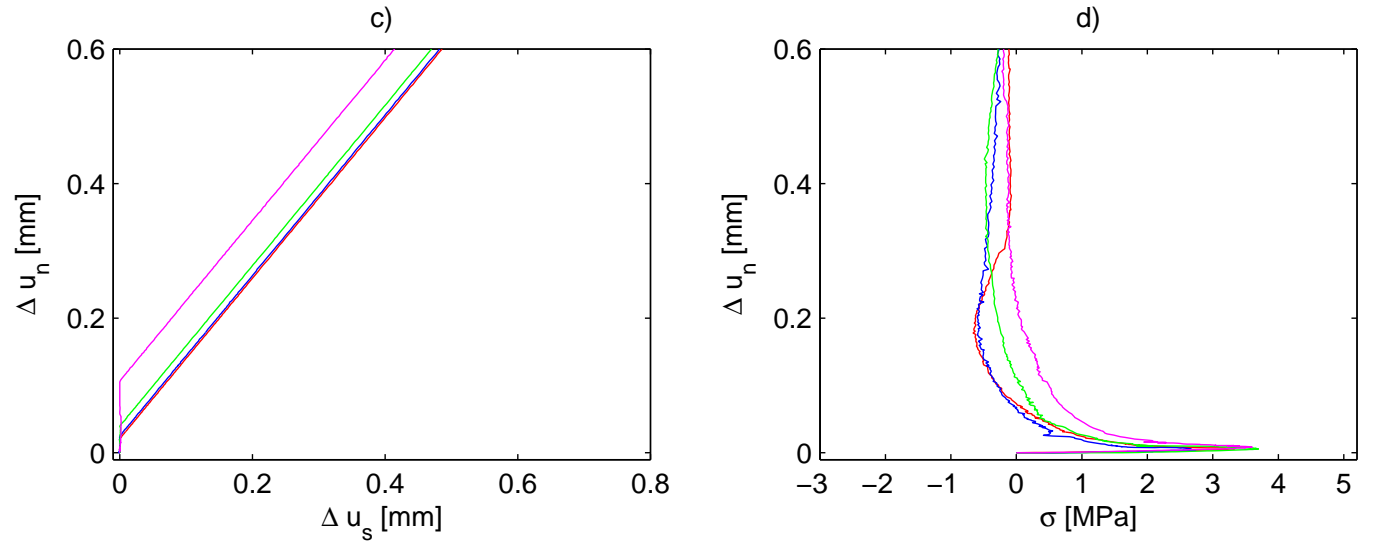

Fig. 13 Mixed mode test results for four different initial openings and the same mixed mode angle of $50^{\circ}$.

Fig. 15 shows tests for the $45^{\circ}$ mixed mode angle at three different initial openings. The same tendencies are seen as in Fig. 14.

Fig. 16 shows tests for the $55^{\circ}$ mixed mode angle at three different initial openings. The compression level and the shear level increases for decreasing initial opening. Despite that the results have been filtered some noise is still present for the $\Delta u_{n}$ $=0.020 \mathrm{~mm}$ test. This noise is most likely a result of the nature of the crack surface as explained in Sect. 3.1.

Fig. 17 shows tests for the $60^{\circ}$ mixed mode angle at three different initial openings. The $\Delta u_{n}=0.015 \mathrm{~mm}$ changes during the test from a ligament crack to a secondary fracture. In the figure this is illustrated by the line style for the result curve which is changed from solid to dashed when the failure mode changes.

\section{References}

1. I. Carol, P.C. Prat, and C.M. López. Normal/shear cracking model: Application to discrete crack analysis. Journal of Engineering Mechanics, 123(8):765-773, 1997.

2. A. Carpinteri and R. Brighenti. Fracture behaviour of plain and fiber-reinforced concrete with different water content under mixed mode loading. Materials \& Design, 31(4):2032 2042, 2010. Design of Nanomaterials and Nanostructures.

3. R. Gettu, B. Mobasher, S. Carmona, and D.C. Jansen. Testing of concrete under closed-loop control. ADVANCED CEMENT BASED MATERIALS, 3(2):54-71, MAR 1996.

4. GOM. Aramis User Manual (4M) v5.4.1. GOM mbH, 2005.
5. M. Hassanzadeh. Behaviour of Fracture Process zones in Concrete Influenced by Simultaneously Applied Normal and Shear Displacements. PhD thesis, Lund Institute of Technology, 1992. Report TVBM-1010.

6. A. Hillerborg. Stability problems in fracture mechanics testing. In S.P.Shah et al., editors, Fracture of concrete and rock - recent developments. London/New York: Elsevier, pages 369-78. London/New York: Elsevier, 1989.

7. A. Hillerborg, M. Modéer, and P.-E. Petersson. Analysis of crack formation and crack growth in concrete by means of fracture mechanics and finite elements. Cement and Concrete Research, 6(6):773-781, 1976.

8. A. Madsen. Cracks in concrete under repetitive load; experiments and modeling. Master's thesis, Department of Civil Engineering, Technical University of Denmark, 2009.

9. L.O. Nielsen, J.F. Mougaard, J.S. Jacobsen, and P.N. Poulsen. A mixed mode model for fracture in concrete. In B.H.Oh et al., editor, Fracture Mechanics of Concrete and Concrete Structures - Recent Advances in Fracture Mechanics of Concrete. Korea Concrete Institute, Seoul, 2010.

10. M.B. Nooru-Muhamed. Mixed Mode Fracture of Concrete: An Experimental Approach. PhD thesis, Delft University, 1992.

11. R.B. Petersen. Fracture mechanical analysis of reinforced concrete. Master's thesis, Department of Civil Engineering. Technical University of Denmark, 2008. Project no. 07-062.

12. H.W. Reinhardt, J. Ozbolt, S. Xu, and A. Dinku. Shear of structural concrete members and pure Mode II testing. Advanced Cement Based Materials, 5(3-4):75-85, 1997. 


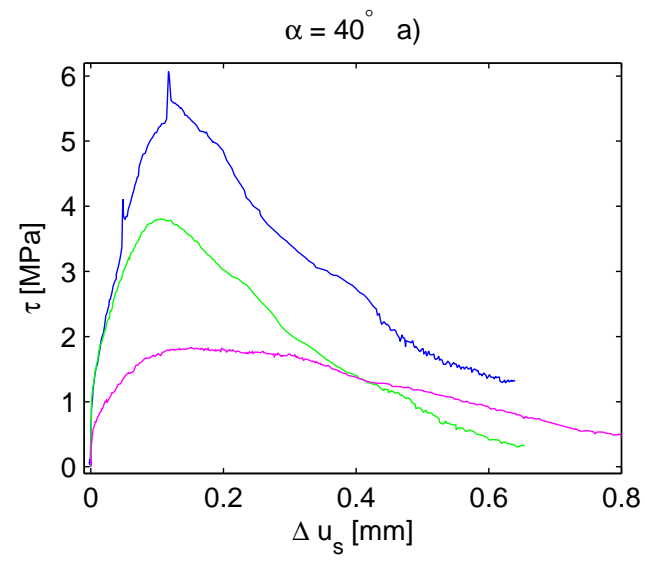

b)

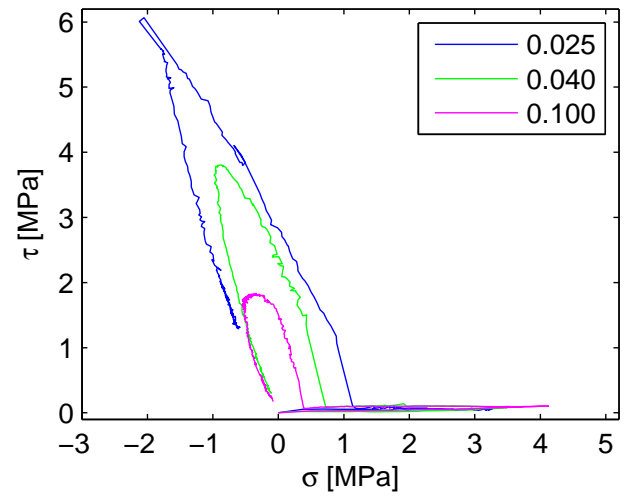

c)

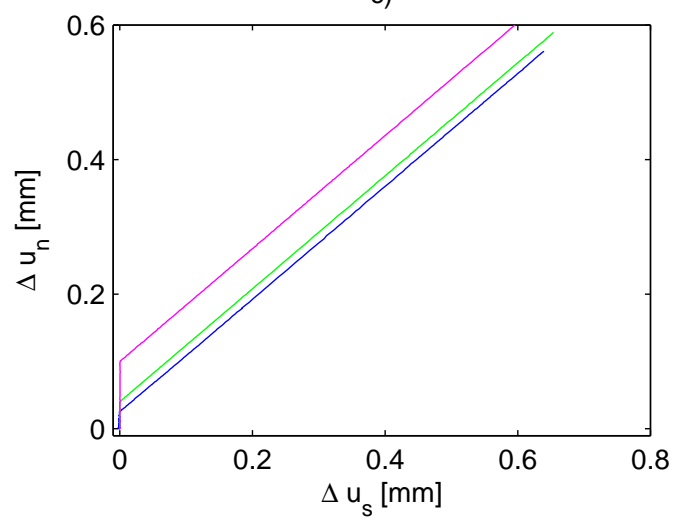

d)

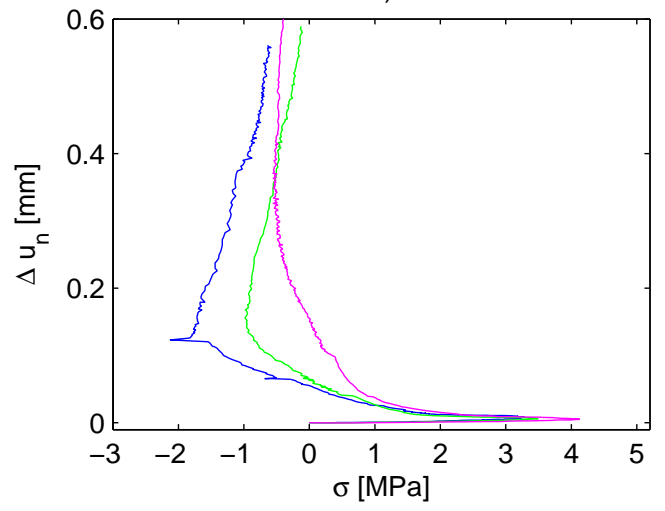

Fig. 14 Mixed mode test results for three different initial openings at the same mixed mode angle of $40^{\circ}$.

13. H.W. Reinhardt and S. Xu. A practical testing approach to determine Mode II fracture energy $\mathrm{G}_{I I f}$ for concrete. International Journal of Fracture, 105(2):107-125, 2000.

14. L. Østergaard, J.F. Olesen, and P.N. Poulsen. Biaxial testing machine for mixed mode cracking of concrete. In Fracture Mechanics of Concrete and Concrete Structures : New Trends in Fracture Mechanics of Concretes., 2007.

15. THK. THK General Catalog, catalog no. 400-1e edition, 2008.

16. R. Walter and J.F. Olesen. Cohesive mixed mode fracture modelling and experiments. Engineering Fracture Mechanics, 75(18):5163-5176, 2008. 


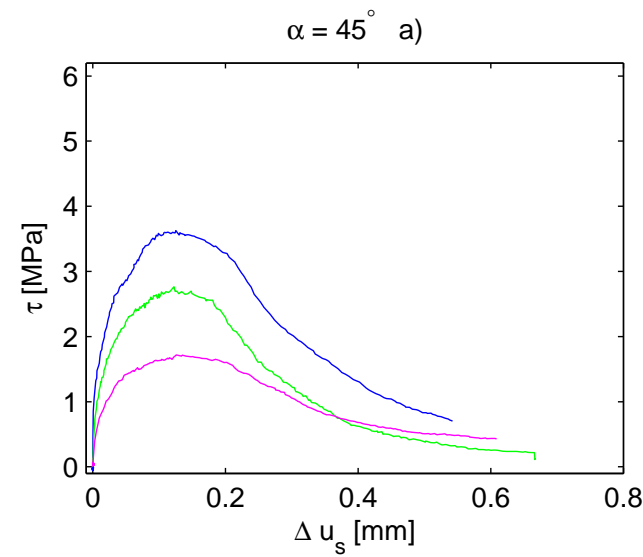

b)

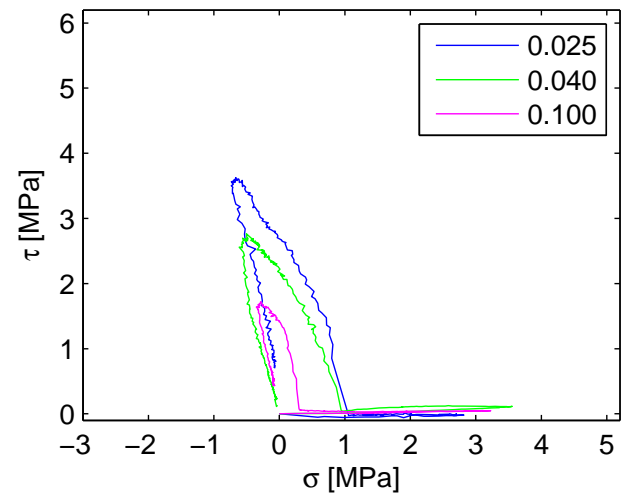

c)
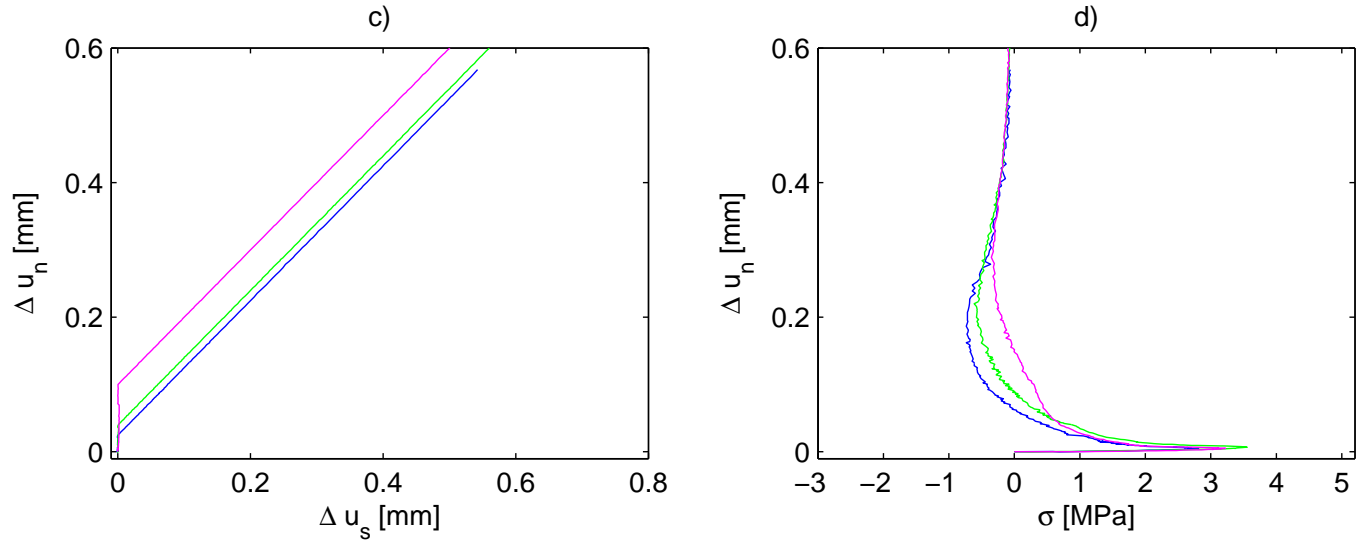

Fig. 15 Mixed mode test results for three different initial openings at the same mixed mode angle of $50^{\circ}$. 


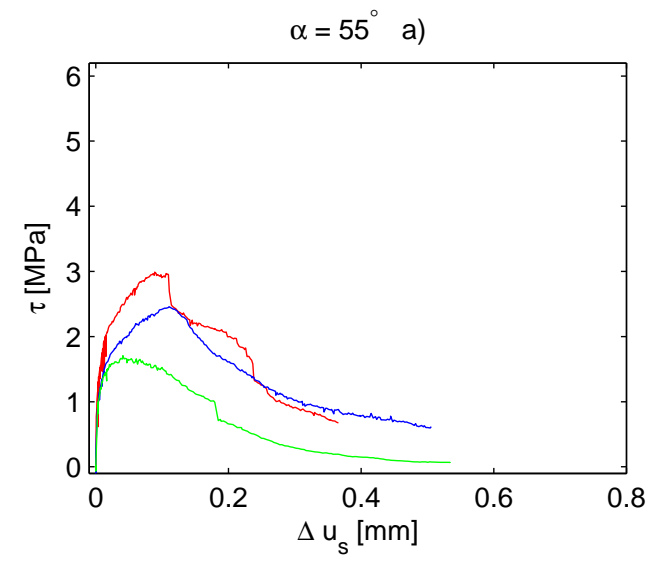

b)
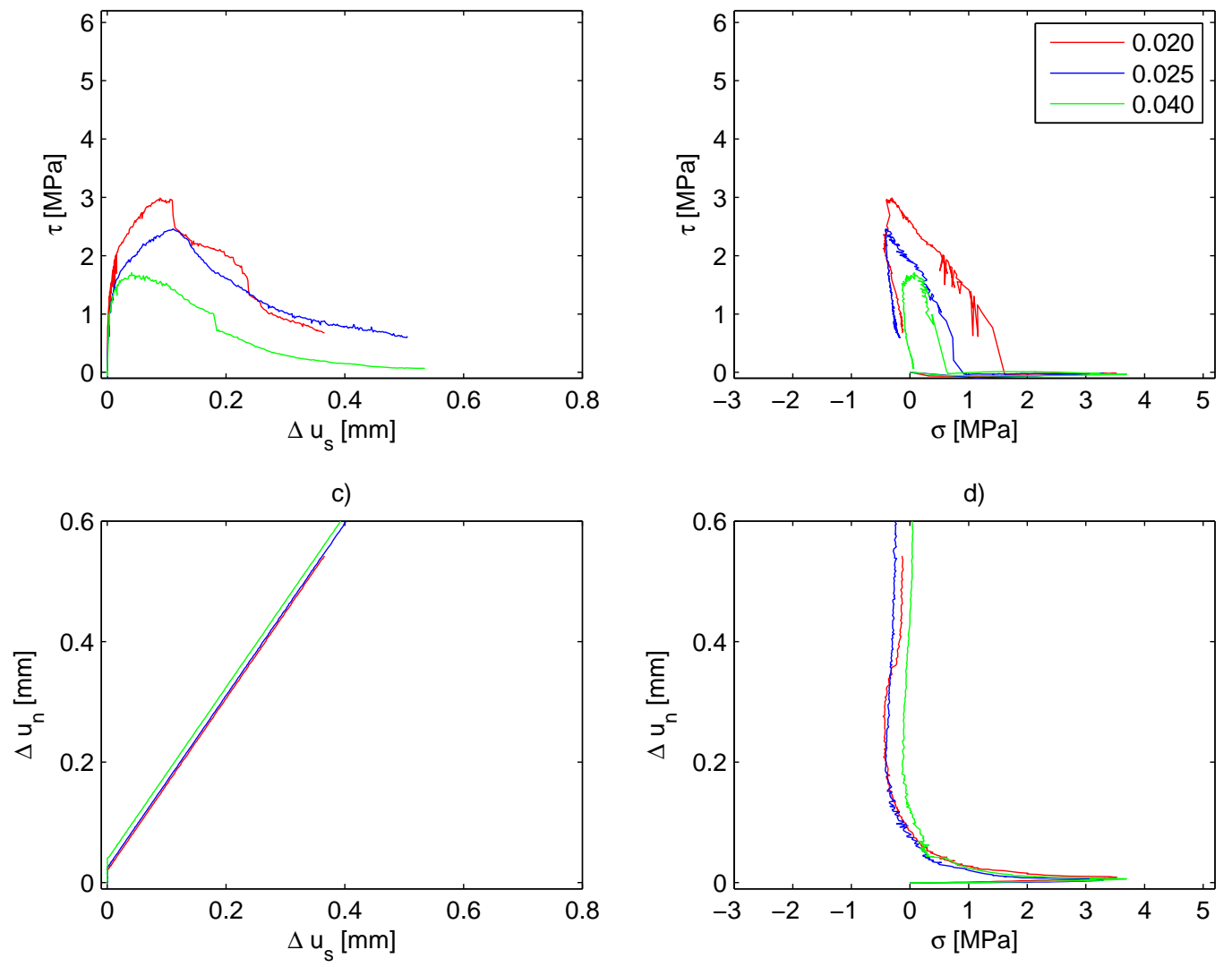

Fig. 16 Mixed mode test results for three different initial openings at the same mixed mode angle of $55^{\circ}$. 


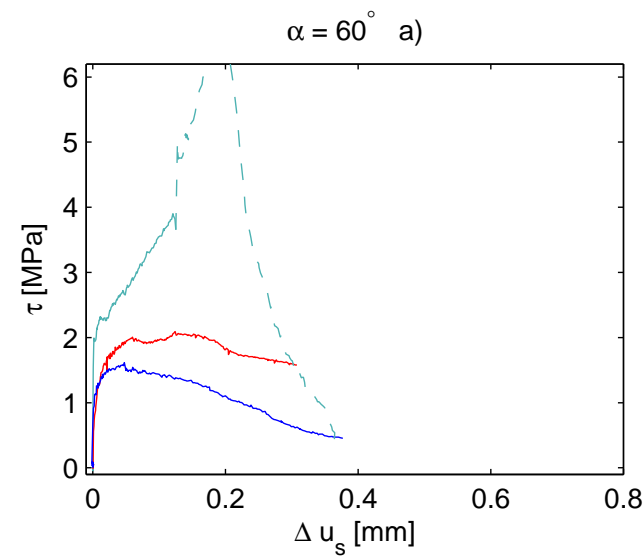

b)
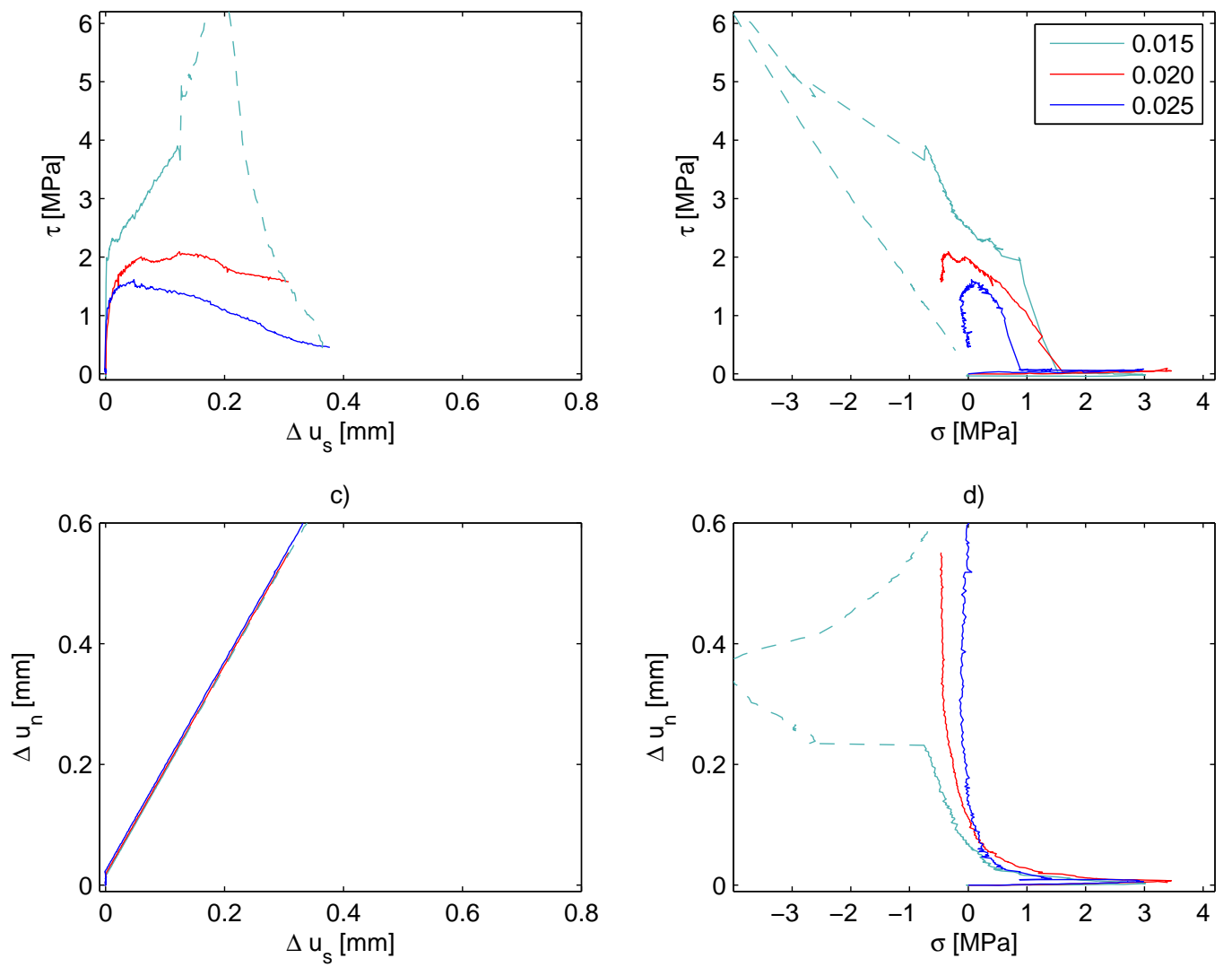

Fig. 17 Mixed mode test results for three different initial openings at the same mixed mode angle of $60^{\circ}$. 